\title{
A Survey and Analysis on the Dormitory Building Environment Indoor Pollution
}

\author{
Bei ZHANG
}

KEYWORD: indoor air quality, volatile organic compounds, respirable particulate matter

ABSTRACT. This experiment by measuring the concentration of volatile organic compounds in the dormitory one day and particulate matter, so we can get through the analysis of the impact of indoor air quality and pollution sources and their distribution, to propose improvement measures. We measured concentrations of pm2.5, pm10 and TVOC, relying TVOC tester and dust instrument.

\section{Introduction}

Using VOC and dust tester to measure indoor pollutants, I measured at different locations and height in different time periods quarters, the concentration of TVOC, pm2.5 and pm10. Firstly, the experiment analyze the influences of different locations TVOC concentrations on the human body, and then analyze the impact pm2.5 pm10 concentration on the human body.The final analysis is of the main factors causing indoor pollution. The conclusion is to achieve the degree of pollution analysis and propose preventive measures and improvement program.

\section{Method}

\subsection{Sample}

In this study, the test object is in a student dormitory of North China Baoding . Haze pollution in the city ranks first in China. Volatile organic compounds are a class of low-boiling organic compounds in general. USEPA definition of VOC is: In addition to carbon dioxide, carbonic acid, metallic carbides, carbonates, and ammonium carbonate and some other carbon-containing compounds involved in atmospheric photochemical reactions outside, including methane, ethane, acetone, methyl acetate and methacrylic acid and so on. Indoor Air Quality Researchers usually define their sampling and analysis of all indoor organic gaseous substances as VOC. Various measured total VOC are known TVOC. VOC mainly comes from indoor building materials circulated, and therefore the indoor VOC concentration is usually higher than outdoor lot. Room TVOC concentration range from usually 50 to 1000 . VOC impact on human health is mainly glasses and respiratory irritation, skin allergies, gives rise to headache, sore throat and fatigue symptoms.

\subsection{Procedure and Measures}

I measured 11-point quarters inside including doors, windows, desktop and so on. Test time is 7:00 am and 18:00, because the hostel two time points pollutant concentration is relatively stable.Experimental data are shown in Table 1 and Table 2:

Table 1:Each measuring point concentration of TVOC at 7:00

\begin{tabular}{|l|l|l|l|l|l|l|l|l|l|l|l|}
\hline \multirow{2}{*}{ Location } & condition & 1 & 2 & 3 & 4 & 5 & 6 & 7 & 8 & 9 & 10 \\
\hline \multirow{2}{*}{ door } & open & 450 & 433 & 407 & 403 & 402 & 403 & 407 & 423 & 446 & 454 \\
\cline { 2 - 12 } & close & 453 & 451 & 447 & 447 & 445 & 452 & 457 & 450 & 456 & 456 \\
\hline \multirow{2}{*}{ aisle } & $1 \mathrm{~m}$ above the ground & 377 & 374 & 369 & 370 & 369 & 370 & 369 & 368 & 369 & 375 \\
\cline { 2 - 11 } & $2 \mathrm{~m}$ above the ground & 385 & 384 & 383 & 384 & 387 & 389 & 387 & 362 & 365 & 366 \\
\hline \multirow{2}{*}{ balcony } & $1 \mathrm{~m}$ above the ground & 411 & 409 & 414 & 431 & 438 & 439 & 435 & 434 & 430 & 428 \\
\cline { 2 - 10 } & $2 \mathrm{~m}$ above the ground & 420 & 421 & 425 & 430 & 434 & 426 & 411 & 396 & 400 & 410 \\
\hline \multirow{2}{*}{ window } & open & 466 & 471 & 476 & 480 & 482 & 482 & 481 & 481 & 482 & 481 \\
\hline
\end{tabular}




\begin{tabular}{|l|l|l|l|l|l|l|l|l|l|l|l|}
\hline \multirow{2}{*}{$\begin{array}{l}\text { Gap between } \\
\text { bed and wall }\end{array}$} & Test Point 1 & 504 & 498 & 501 & 495 & 494 & 491 & 492 & 493 & 501 & 499 \\
\cline { 2 - 12 } & Test Point 2 & 524 & 526 & 530 & 532 & 536 & 537 & 540 & 539 & 538 & 537 \\
\hline \multirow{2}{*}{ desktop } & Test Point 1 & 474 & 470 & 472 & 469 & 462 & 442 & 427 & 420 & 416 & 415 \\
\cline { 2 - 11 } & Test Point 2 & 367 & 367 & 367 & 368 & 370 & 373 & 380 & 387 & 401 & 411 \\
\hline
\end{tabular}

The unit of data in the table is $\mu \mathrm{g} / \mathrm{m}^{3}$.

Table 2:Each measuring point concentration of TVOC at 18:00

\begin{tabular}{|c|c|c|c|c|c|c|c|c|c|c|c|}
\hline Location & condition & 1 & 2 & 3 & 4 & 5 & 6 & 7 & 8 & 9 & 10 \\
\hline \multirow{2}{*}{ door } & open & 462 & 450 & 446 & 448 & 451 & 456 & 457 & 458 & 459 & 449 \\
\hline & close & 495 & 495 & 495 & 496 & 495 & 495 & 492 & 492 & 492 & 492 \\
\hline \multirow{2}{*}{ aisle } & $1 \mathrm{~m}$ above the ground & 259 & 284 & 296 & 297 & 302 & 314 & 321 & 322 & 321 & 324 \\
\hline & $2 \mathrm{~m}$ above the ground & 417 & 419 & 418 & 420 & 420 & 416 & 418 & 417 & 413 & 394 \\
\hline \multirow{2}{*}{ balcony } & $1 \mathrm{~m}$ above the ground & 332 & 328 & 324 & 320 & 317 & 315 & 314 & 315 & 321 & 328 \\
\hline & $2 \mathrm{~m}$ above the ground & 414 & 423 & 429 & 428 & 422 & 412 & 401 & 411 & 415 & 415 \\
\hline window & open & 414 & 415 & 413 & 413 & 417 & 421 & 419 & 417 & 416 & 417 \\
\hline \multirow{2}{*}{$\begin{array}{l}\text { Gap between } \\
\text { bed and wall }\end{array}$} & Test Point 1 & 510 & 513 & 513 & 517 & 519 & 521 & 520 & 517 & 517 & 517 \\
\hline & Test Point 2 & 568 & 568 & 569 & 570 & 571 & 572 & 570 & 572 & 579 & 581 \\
\hline \multirow{2}{*}{ desktop } & Test Point 1 & 412 & 415 & 416 & 416 & 416 & 420 & 418 & 409 & 411 & 412 \\
\hline & Test Point 2 & 414 & 415 & 413 & 413 & 417 & 421 & 419 & 417 & 416 & 417 \\
\hline
\end{tabular}

The unit of data in the table is $\mu \mathrm{g} / \mathrm{m}^{3}$.

I measured concentration of TVOC at the same place and ground level but different time. Explore the method of control variables change in different time TVOC, and calculate the average TVOC obtain curve shown in Figure 1:

Figure 1 The average concentration of TVOC

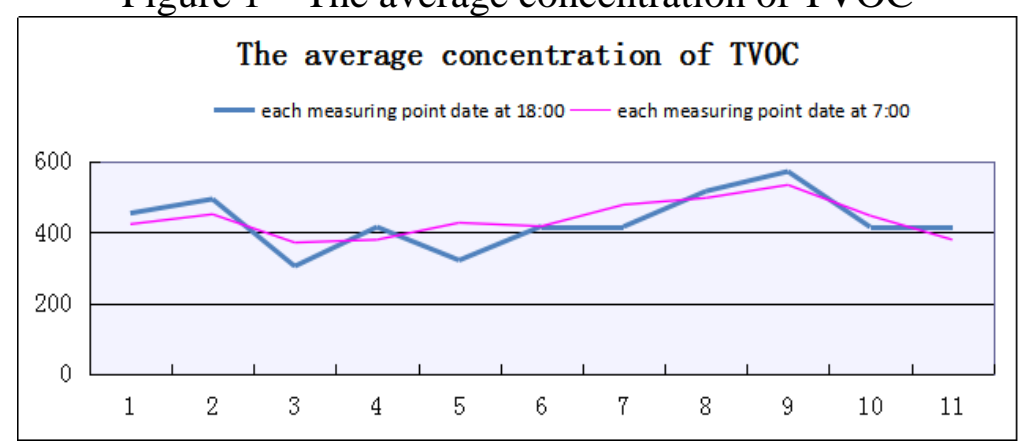

By analyzing the images I can get some conclusions. In the evening, the average concentration of TVOC measuring points 1,2,4,9,11 were higher than in the morning, however, the measuring point 3,5,7,10 the opposite. Therefore, in the morning and evening time of day segments, changes in indoor TVOC concentrations not a correlation. We can think of TVOC concentration values of these two time periods little change, which ensures that we do not receive in a day when other factors affect the decoration. Indoor air TVOC basically in a stable state, at different times, and it has no significant trends.

Next, I did a comprehensive analysis of TVOC concentrations dormitory staff work and study area. In this indoor TVOC concentrations measured in the experiment, we measured the two students TVOC concentrations in the air in at 18:00 on the desktop, and research personnel in the dormitory when the breathing air quality. Sorting through the data obtained in the following figure 2 . 
Figure 2 The concentration of TVOC

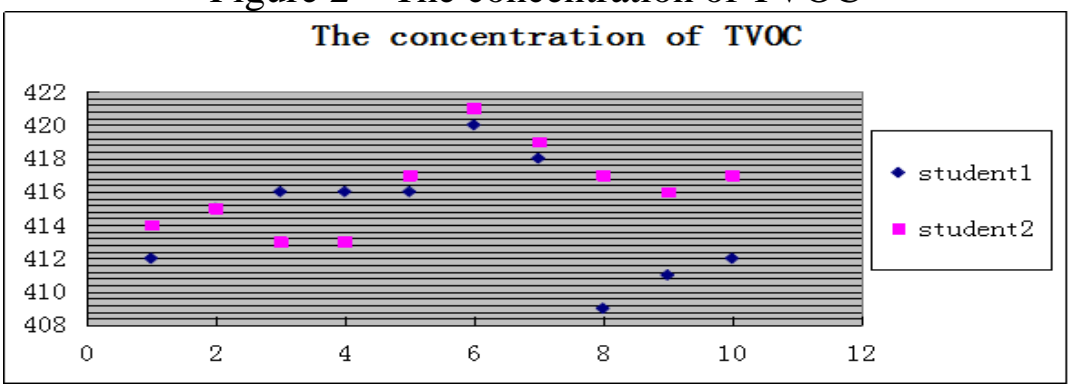

Table 3:Relationship of TVOC concentration and reaction of the human body

\begin{tabular}{|l|l|l|}
\hline $\begin{array}{l}\text { The concentration of } \\
\text { TVOC }\end{array}$ & Health Effects & classification \\
\hline$<200$ & No stimulation, no discomfort & Cozy \\
\hline $200-3000$ & $\begin{array}{l}\text { When combined effects with other factors, it } \\
\text { may appear irritation and discomfort } \\
\text { by synergies }\end{array}$ \\
\hline $3000-25000$ & $\begin{array}{l}\text { Headache may occur when the combined } \\
\text { effects with other factors }\end{array}$ & Unwell \\
\hline$>25000$ & $\begin{array}{l}\text { The exception of headache, may have other } \\
\text { neurotoxic effects }\end{array}$ & Poisoning \\
\hline
\end{tabular}

From Figure 2, we can visually see the changes in the scope of TVOC concentration is $409 \sim 421$, combined with Table 3 quarters were likely due to the synergistic effect appears more irritation and discomfort, we do combine at the location. Conclusions might cause headaches, dizziness and other symptoms in the haze and other factors. Solutions are learning or life process should increase exercise, do not be in a place for long periods.

Determination of indoor pm2.5 and pm10 concentration of the raw data

Table 4:Each measuring point concentration of pm10 at 18:00

\begin{tabular}{|l|l|l|l|l|l|l|l|l|l|l|l|}
\hline \multirow{2}{*}{ Location } & condition & 1 & 2 & 3 & 4 & 5 & 6 & 7 & 8 & 9 & 10 \\
\hline \multirow{2}{*}{ door } & open & 151 & 125 & 124 & 123 & 119 & 113 & 112 & 115 & 128 & 125 \\
\cline { 2 - 14 } & close & 88 & 89 & 86 & 101 & 104 & 106 & 105 & 103 & 101 & 100 \\
\hline aisle & 1 m above the ground & 124 & 125 & 124 & 123 & 119 & 113 & 112 & 115 & 128 & 129 \\
\hline balcony & 1 m above the ground & 168 & 165 & 166 & 172 & 169 & 170 & 170 & 169 & 169 & 169 \\
\hline \multirow{2}{*}{ window } & open & 212 & 208 & 215 & 209 & 213 & 212 & 210 & 211 & 213 & 212 \\
\hline \multirow{2}{*}{$\begin{array}{l}\text { Gap between } \\
\text { bed and wall }\end{array}$} & Test Point 1 & 117 & 119 & 121 & 125 & 124 & 123 & 120 & 119 & 119 & 120 \\
\cline { 2 - 12 } & Test Point 2 & 107 & 109 & 110 & 111 & 108 & 111 & 109 & 110 & 111 & 112 \\
\hline \multirow{2}{*}{ desktop } & Test Point 1 & 98 & 99 & 98 & 101 & 100 & 102 & 103 & 105 & 106 & 104 \\
\cline { 2 - 11 } & Test Point 2 & 118 & 115 & 117 & 120 & 122 & 123 & 125 & 123 & 124 & 120 \\
\hline
\end{tabular}

Table 5:Each measuring point concentration of pm2.5 at 18:00

\begin{tabular}{|l|l|l|l|l|l|l|l|l|l|l|l|}
\hline Location & condition & 1 & 2 & 3 & 4 & 5 & 6 & 7 & 8 & 9 & 10 \\
\hline \multirow{2}{*}{ door } & open & 85 & 86 & 85 & 86 & 87 & 85 & 87 & 86 & 85 & 84 \\
\cline { 2 - 15 } & close & 60 & 61 & 62 & 63 & 67 & 67 & 64 & 62 & 61 & 59 \\
\hline aisle & 1 m above the ground & 70 & 69 & 70 & 69 & 70 & 69 & 70 & 70 & 72 & 73 \\
\hline balcony & 1 m above the ground & 115 & 110 & 112 & 111 & 112 & 111 & 113 & 110 & 109 & 108 \\
\hline \multirow{2}{*}{ window } & open & 233 & 234 & 235 & 236 & 239 & 241 & 243 & 249 & 252 & 254 \\
\hline \multirow{2}{*}{$\begin{array}{l}\text { Gap between } \\
\text { bed and wall }\end{array}$} & Test Point 1 & 69 & 70 & 72 & 73 & 76 & 75 & 74 & 73 & 75 & 77 \\
\cline { 2 - 14 } & Test Point 2 & 75 & 77 & 78 & 80 & 79 & 78 & 76 & 75 & 74 & 72 \\
\hline \multirow{2}{*}{ desktop } & Test Point 1 & 66 & 64 & 63 & 60 & 60 & 57 & 56 & 58 & 59 & 62 \\
\cline { 2 - 12 } & Test Point 2 & 75 & 74 & 75 & 74 & 72 & 75 & 74 & 73 & 73 & 74 \\
\hline
\end{tabular}


Indoor pm2.5 and pm10 gathering analysis is the primary task.Due to environmental conditions in the room is single, so I chose the indoor and outdoor at the interface as a data point to compare and analyze the secondary distribution of indoor respirable particulate matter. I put the area into three. The first area is the dormitory hallway, hostel desktop dormitory door closed state, the gap bed and the wall. The second area is the balcony, this is the boundary between the outdoor and indoor. The third area is the balcony window that is open outdoor environment. I am pm2.5 and pm10 analysis and comparison of the three regions get Figure 3 and 4.

Figure 3 and 4 The concentration of pm2.5 and pm10

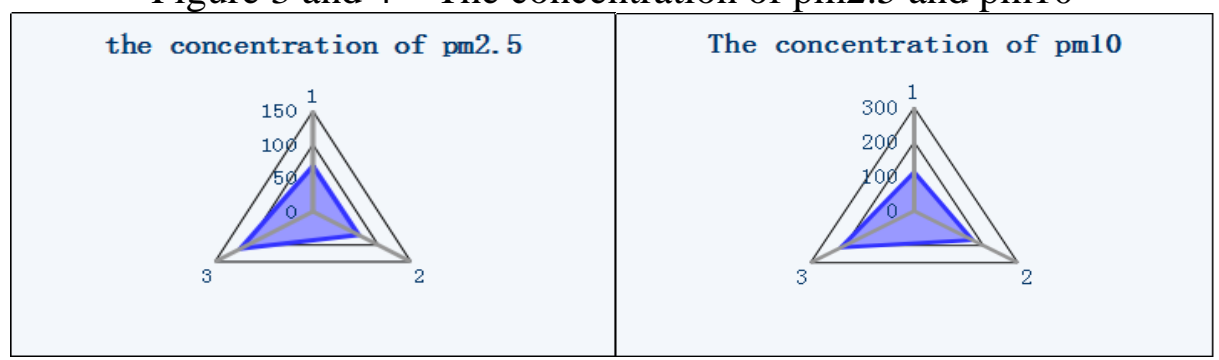

By analyzing the picture, I can get a conclusion. pm2.5 and pm10 concentration distribution in the region is higher than the third one, two regions, but also pm2.5 distribution concentration in the second region is large.

\section{Conclusion}

TVOC in the indoor environment from the outdoor air may enter or emanating from building materials, cleaning agents, cosmetics, wax products, interior paint, so we should not enter the dormitory renovations such as painting the walls after some time in the open window ventilation to effectively remove TVOC, regular cleaning in the gap at the bed and the wall, prevention of harmful substances gathering. After another period of study compare to breathe fresh air, to prevent headaches and other symptoms.

\section{References}

[1]J. P. Yang. Research on University Library Core Competitiveness Based on Knowledge Management [J]. Library Research \& Work, 2010.167:18-21.

[2] Z. S. Liu. Hong Kong Baptist University Library Subject Librarian System Research [J].Library, 2016,4:13-18 2011,21,(19):62-64

[3] X. W. Zhan. Core Competence of Subject Librarians on Building Library [J].Journal of Sichuan University of Science \& Engineering, 2008.23(12):68-70.

[4] G. S. Zhang. Research on the Needs of Knowledge Structure and Knowledge Hierarchy for University Library Subject Librarian [J]. Sci-Tech Information Development \& Economy 